\title{
Design Performance of High Speed Optical Fiber WDM System with Optimally Placed DCF for Dispersion Compensation
}

\author{
Mulayam Yadav \\ M.Tech Student of \\ ECE, SSET/ SHIATS \\ Allahabad, \\ U.P.211007. INDIA
}

\author{
A.K. Jaiswal \\ Prof.\& Head \\ ECE,SSET/SHIATS, \\ Allahabad U.P, \\ 211007.INDIA
}

\author{
Neelesh Agrawal \\ Assistant Prof.of \\ ECE, SSET/SHIATS, \\ Allahabad, U.P, \\ 211007. INDIA
}

\author{
Navendu Nitin \\ Assistant Prof.of ECE, \\ SSET/SHIATS, \\ Allahabad, U.P, \\ 211007. INDIA
}

\begin{abstract}
Diverse factors like chromatic dispersion, polarization mode dispersion, attenuation, non-linear effects, second order and third order dispersion impress limit on the performance of all the optical fiber networks. Dispersion compensation fiber are being used in this paper, we projected three techniques (pre, post, and mix-compensation of dispersion compensation) of dispersion compensation methods for non-return to zero links using standard for high date rate optical transmission system. The performances have been compared on the basis of parameters such as $\mathrm{Q}$ factor, bit error rate (BER), eye height and threshold level at the receiving end. The simulation model of the WDM system using the software Optisystem 12.0 is presented according to the above principle. It is observed that the post-compensation technique performs better than pre-, mix-compensation technique for $40 \mathrm{~Gb} / \mathrm{s}$ in the WDM system.
\end{abstract}

\section{Keywords}

BER, dispersion compensation, optical communication DCF, Q-factor, WDM

\section{INTRODUCTION}

In the modern era, the information and communication networks are one of the emerging technologies in the world. As there is rapid growth in the number of internet users, the systems with more capacity are required. The key features that make a system effective are its availability and utilization of bandwidth. Fiber optics networks are such networks that can meet the growing needs for the communication field having enormous bandwidth potential and good transmission performance.

Consequently the demand for transmission capability and bandwidth are becoming more and more challenging to the carriers and service suppliers. Under the situation, with its enormous bandwidth and excellent transmission performance optical fiber communication is becoming the most favorable delivering media and playing more and more important role in information industry $[3,4]$.

Therefore, it is very necessary to investigate the transmission characteristics of optical fiber where in the most important goal of communication system is to increase the transmission distance. Loss and dispersion are the two foremost factors that affect fiber-optical communication system which provide high system capacity. The EDFA is the gigantic alter happen in the fiber-optical communication system. The loss is no longer the main factor to restrict the fiber optical broadcast system. While EDFA works in $1550 \mathrm{~nm}$ wave band, where the standard Single Mode Fiber (SMF) dispersion value is large, about 15-20ps / (nm.km). It is easy to see that the dispersion becomes the major factor that restricts long distance fiber optical transfers. [5]. in this paper, we intend three DCF compensation techniques, post-compensation, precompensation and symmetrical/mix compensation techniques. Simulation study show that post compensation proposal is the most appropriate.

The paper is prepared as follows. In Section 2, the cause of fiber dispersion and its effects on optical transmission is introduced. In Section 3, present Fiber dispersion compensation technology is described. Section 4, present the most recent research of DCF dispersion compensation scheme. Section 5 present transmission system simulation with software OPTISYSTEM 12, analyses and compare each kind of compensation technique, Section 6 concludes the paper.

\section{EFFECT OF FIBER-OPTIC DISPERSION ON OPTICAL TRANSMISSION}

Loss and dispersion are the two most important factors that affect the fiber-optical communication system. Dispersion occurs due to different frequency or mode of light pulse in fiber propagating at different rates, so that these frequency components or models arrive the fiber terminals at different instant of time. It can cause intolerable amounts of pulse broadening causing distortions that ultimately lead to errors. In single-mode fiber, performance is primarily limited by chromatic dispersion which occurs because the index of the glass varies slightly depending on the wavelength of the light, as the light from real optical transmitter necessarily has nonzero spectral width. Polarization mode dispersion, another source of limitation occurs because although the single-mode fiber can sustain only one transverse mode, it can be carried with two different polarizations, and slight imperfections or distortions in a fiber can alter the propagation velocities for these two polarizations, This phenomenon is called polarization mode dispersion and Mode birefringence $\mathrm{Bm}$ is defined as the follow

$$
B_{m}=\frac{\beta_{x}-\beta_{y}}{k_{0}}=\left(n_{x}-n_{y}\right)
$$

Where $\mathrm{n}_{\mathrm{x}}, \mathrm{n}_{\mathrm{y}}$ are the effective refractive of the two orthogonal polarizations. For a given $\mathrm{Bm}$, its fast axis and slow axis components would develop the phase difference after the light waves transmission $\mathrm{L} \mathrm{Km}$.

$$
\varphi=k_{0} B_{m} L=\frac{2 \pi}{\lambda}\left(n_{x}-n_{y}\right) L=(\beta \mathrm{x}-\beta \mathrm{y}) \mathrm{L}
$$


If the $\mathrm{Bm}$ remains constant. The phase difference between its fast axis and slow axis will be periodically repeated. The length that it leads to a phase difference of $2 \pi$ or power periodic exchange is called polarization beat length.

$$
\mathrm{L}_{\mathrm{B}}=\frac{2 \pi}{\left|\beta_{x}-\beta_{y}\right|}=\frac{\lambda}{B_{m}}
$$

If the incident light has two polarization components, due to refractive difference between the fast axis and slow axis, the transmit rate of two polarization components will be different. Degree of pulse broadening can be expressed by different group delay $\Delta \tau$. The influence of dispersion on system performance is also reflected in the optical fiber nonlinear effects. Dispersion increase the pulse shape distortion caused by the self-phase modulation (SPM), dispersion in WDM systems can also increase the cross-phase modulation (XPM), four-wave mixing (FWM) and other nonlinear effects [7,8]. Pre compensation: In this Compensation technique the dispersion compensating fiber of negative dispersion is placed before the standard fiber to compensate positive dispersion of the standard fiber. Post-Compensation: In this Compensation design, the dispersion compensating fiber of negative dispersion is placed after the standard fiber to compensate positive dispersion of the standard fiber. In the mix Compensation design, the dispersion compensating fiber of negative dispersion is placed before and after the standard fiber to compensate positive dispersion of the standard fiber [8].

\section{DISPERSION COMPENSATION TECHNOLOGY (DCF)}

To improve overall system performance with compact as possible in the optical communication system performance influenced by the dispersion, several dispersion compensation technologies were proposed [12]. Amongst the various techniques proposed in the literature, the ones that appear to hold immediate promise for dispersion compensation and management could be broadly classified as: dispersion compensating fiber (DCF), chirped fiber Bragg gratings (FBG), and high-order mode (HOM) fiber. The idea of using dispersion compensation fiber for dispersion compensation was proposed as early as in 1980 but, until after the invention of optical amplifiers, DCF began to be widespread attention for long distance transmission over the optical fiber communication system. DCF has become a most useful method of dispersion compensation and has been extensively studied. There is positive second-order and third-order dispersion value in SMF while the DCF dispersion value is negative. So by inserting a DCF, the average dispersion is brought close to zero [13]. As the local dispersion of higher transmission link, FWM and XPM were ignored, only to consider the role of SPM and dispersion.

\section{DISPERSION COMPENSATION SCHEME}

To support a high-capacity wavelength-division-multiplexing (WDM) transmission, the implanted standard single-mode fiber (SMF) should be up graded to overcome the dispersion limit. In this paper three different dispersion compensation techniques analyzed with help of DCF at a different frequency range. According to relative position of DCF and single mode fiber, post-compensation, pre-compensation and symmetrical/mix compensation are projected. DCF Precompensation scheme achieve dispersion compensation by placing the DCF before a certain conventional single-mode fiber after the optical transmitter. Post compensation scheme achieve dispersion compensation by placing the DCF after a certain conventional single-mode fiber, or before the optical transmitter. Symmetrical/mix compensation scheme consist of post compensation and pre compensation. Different location on the system will generate different nonlinear effects. The Simulation figure of three dispersion compensation scheme is shown in

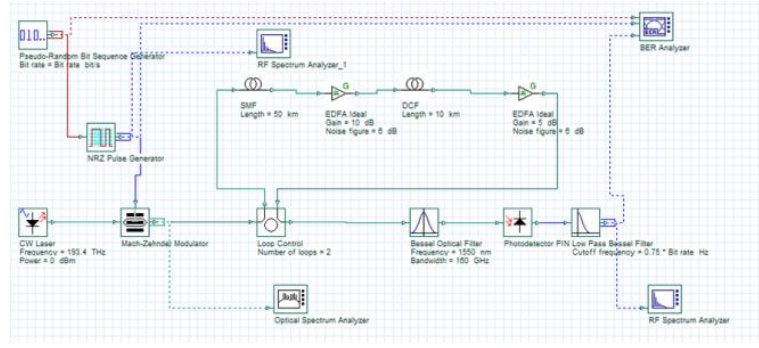

(a) Simulation for post compensation

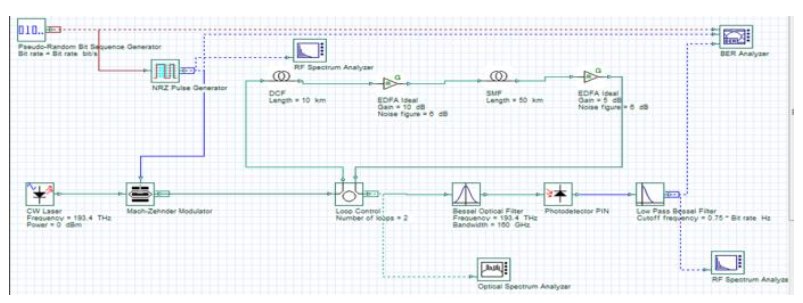

(b) Simulation for pre compensation

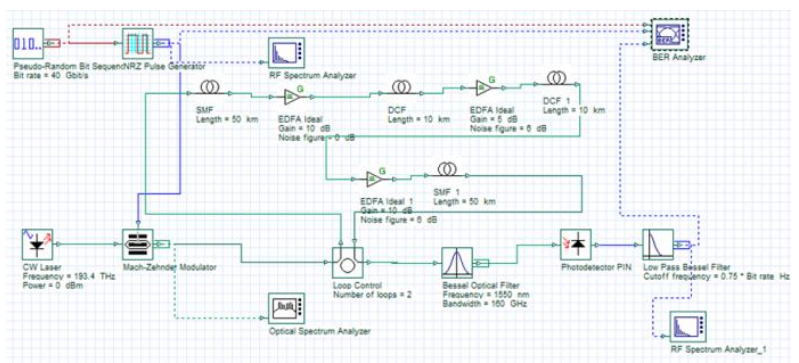

(c) Simulation for mix compensation

Figure 1: Three dispersion compensation techniques

The simulation tool used for comparing the different dispersion compensation techniques under study is OPTISYSTEM 12.0 Figure 1 (a) shows the post compensation schemes. The simulation module includes the transmission module, transmission link and the receiver module. Simulation model use Mach-Zehnder external modulator to modulate the $\mathrm{CW}$ Laser at central frequency 193.4 THz. Optical fiber transmission link composed of a $50 \mathrm{Km}$. The standard single mode fiber G.655 is used. Dispersion compensation is achieved and implemented using dispersion compensated fiber (DCF). EDFA is used to compensate the power loss generating by SMF and the DCF signal. Receiver module includes de multiplexer and receiver filters. Figure 1 (b) and Figure 1 (c) respectively show the pre compensation scheme and the symmetrical/mix compensation scheme. The simulation configuration is as similar as Figure 1 (a). The difference is that at the transmitter DCF compensate $50 \mathrm{Km}$ of single-mode fiber dispersion in Figure 1 (b). In Figure 1 (c), there is a symmetrical/mix compensation scheme. 


\section{RESULTS AND ANALYSIS}

In fiber optic communication, only optical signal to noise ratio (OSNR) could not precisely determine the system performance, particularly in WDM systems. The three dispersion compensation techniques have been analyzed at 40 Gbps for different terms such as bit error rate (BER), Qfactor, eye height and threshold level. The eye diagrams for the pre-, post- and symmetrical/mix-compensation are shown in this fig. The graphs for BER, Q-factor, eye height and threshold level for all the users with the three techniques are shown in "Fig.3".

Quality factor is one of the significant indicators to measure the optical wave performance to describe the BER. Fig (2) shows the comparison $Q$ factor with varied frequency in three different compensation techniques.

It is observed that by varying the frequency of optical source, the $\mathrm{Q}$ factor are affected in all the three compensation techniques. It is observed that with input frequency increasing from 193.0 to $193.4 \mathrm{THz}$ brings the gradual rise in Q- factor and when input cw laser frequency approaches to $193.4 \mathrm{THz}$, the Q- factor becomes maximum. At the same frequency used in the three different compensation techniques, it is observed that the Q- factor of post compensation technique is largest than in the two other kinds of dispersion compensation techniques.

When the input cw laser frequency is greater than $193.4 \mathrm{THz}$ the quality factor decrease gradually and the bit error rate performance is gradually degraded as indicated table no. (1).

Overall study of the performance reveals that the performance of post compensation technique is superior in the long distance high speed WDM system.

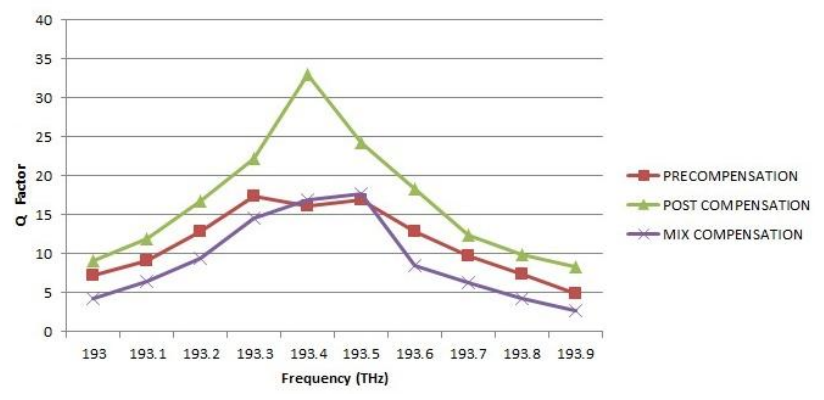

Figure (2) Comparison of frequency manipulate of three compensation techniques
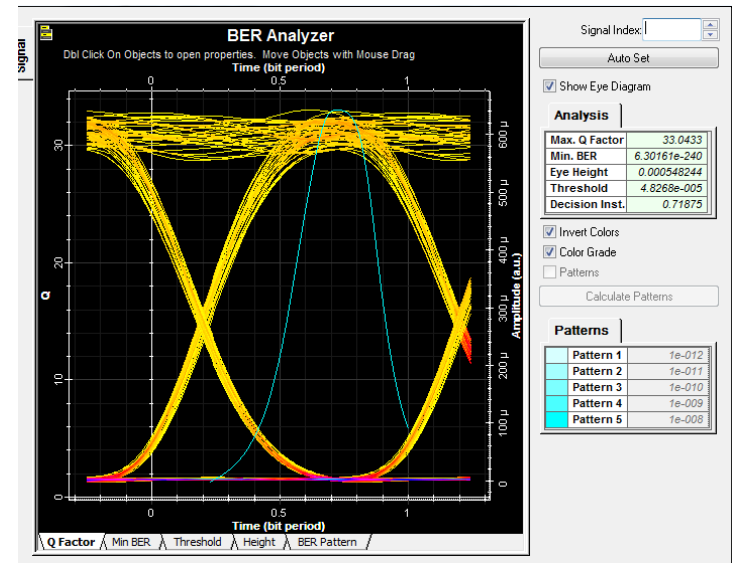

(a)

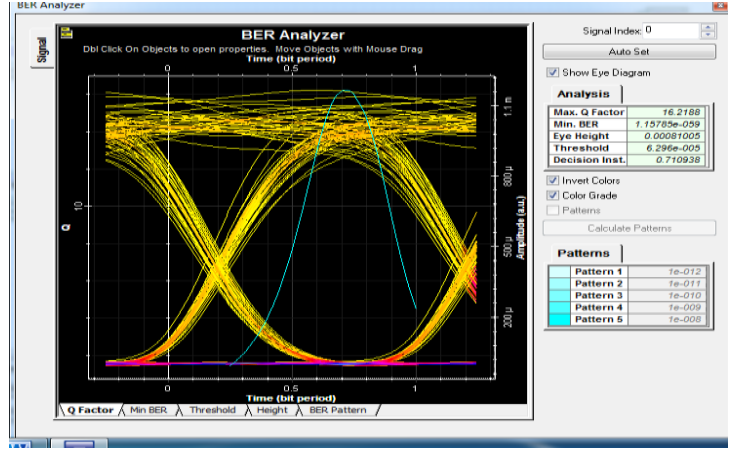

(b)

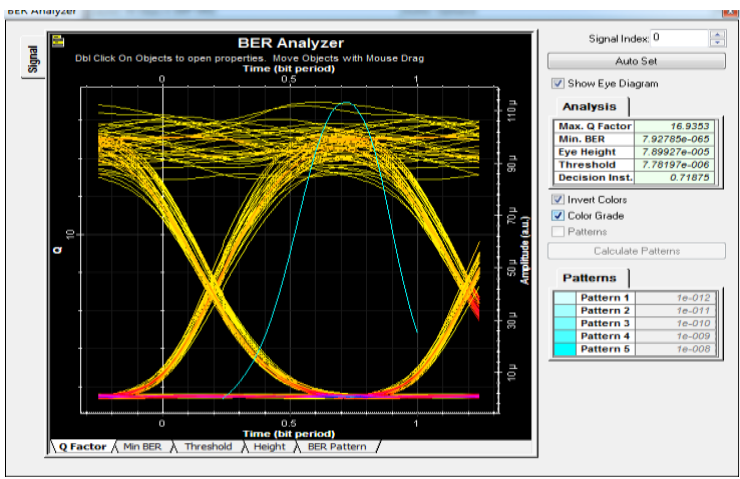

(c)

Figure. (3) Eye diagrams of (a) post- compensation (b) Pre-compensation and (c) mix- compensation At frequency $(193.4 \mathrm{THz})$

The table 1 brings the comparative analysis of pre, post and mix compensation technique which is analyzed with software optisystem 12. The configuration employed in the compensation technique are design using transmitter of signal by cw laser with frequency $193.4 \mathrm{THz}$ and power of $0 \mathrm{dbm}$, also the pseudo-random bit NRZ pulse generator with given bit rate. Comparisons of dispersion compensation technique are achieved by analyzing at the different frequency range of $\mathrm{CW}$ laser.

The graph obtained by the analysis at $193.4 \mathrm{THz}$ of pre, post and mix compensation techniques shows the $\mathrm{Q}$ factor at post compensation to be 33.0433 and BER achieve $6.3016 \mathrm{e}^{-240}$ with the maximum $\mathrm{Q}$ factor is obtain using post compensation at frequency $193.4 \mathrm{THz}$. As such frequency range among at the varied frequency of input $\mathrm{CW}$ laser used at $193.0 \mathrm{THz}$, 193.20 THz, $193.4 \mathrm{THz}, 193.6 \mathrm{THz} \& 193.8 \mathrm{THz}$.as shown at table no.1.

Table.1. Comparison of three different techniques at different frequency range At 193.0 THz

\begin{tabular}{|c|c|c|c|c|}
\hline $\begin{array}{l}\text { Sr.N } \\
\text { o. }\end{array}$ & Parameter & $\begin{array}{l}\text { Pre- } \\
\text { compensat } \\
\text { ion }\end{array}$ & $\begin{array}{l}\text { Post- } \\
\text { compensat } \\
\text { ion }\end{array}$ & $\begin{array}{l}\text { mix- } \\
\text { compensat } \\
\text { ion }\end{array}$ \\
\hline 1 & $\begin{array}{l}\text { Q- } \\
\text { FACTOR }\end{array}$ & 7.30743 & 9.07705 & 4.34487 \\
\hline 2 & BER & $\begin{array}{l}1.34617 \mathrm{e}- \\
013\end{array}$ & $\begin{array}{l}5.48299 \mathrm{e}^{-} \\
020\end{array}$ & $\begin{array}{l}6.92925 \mathrm{e}^{-0} \\
06\end{array}$ \\
\hline 3 & $\begin{array}{l}\text { EYE } \\
\text { HEIGHT }\end{array}$ & $\begin{array}{l}2.35816 \mathrm{e}^{-} \\
005\end{array}$ & ${ }_{005}^{1.54585 \mathrm{e}^{-}}$ & $\begin{array}{l}1.06652 \mathrm{e}- \\
006\end{array}$ \\
\hline 4 & $\begin{array}{l}\text { THRESHO } \\
\text { LD }\end{array}$ & $\begin{array}{l}2.00831 \mathrm{e}^{-} \\
005\end{array}$ & $1.27153 \mathrm{e}^{-}$ & $2.6639 \mathrm{e}^{-006}$ \\
\hline
\end{tabular}


At 193.2 THz

\begin{tabular}{|l|l|l|l|l|}
\hline $\begin{array}{l}\text { Sr.N } \\
\text { o. }\end{array}$ & Parameter & $\begin{array}{l}\text { Pre- } \\
\text { compensat } \\
\text { ion }\end{array}$ & $\begin{array}{l}\text { Post- } \\
\text { compensat } \\
\text { ion }\end{array}$ & $\begin{array}{l}\text { mix- } \\
\text { compensat } \\
\text { ion }\end{array}$ \\
\hline 1 & $\begin{array}{l}\text { Q- } \\
\text { FACTOR }\end{array}$ & 12.9381 & 16.7705 & 9.48509 \\
\hline 2 & BER & $\begin{array}{l}1.23848 \mathrm{e}- \\
038\end{array}$ & $\begin{array}{l}1.82941 \mathrm{e}- \\
063\end{array}$ & $\begin{array}{l}1.16045 \mathrm{e}- \\
021\end{array}$ \\
\hline 3 & EYE & 0.0001075 & $6.33934 \mathrm{e}-$ & $\begin{array}{l}8.84319 \mathrm{e}- \\
006\end{array}$ \\
& HEIGHT & 74 & 005 & 006 \\
\hline 4 & THRESHO & $\begin{array}{l}4.32667 \mathrm{e}- \\
005\end{array}$ & $\begin{array}{l}2.62003 \mathrm{e}- \\
005\end{array}$ & $\begin{array}{l}5.89896 \mathrm{e}- \\
006\end{array}$ \\
& LD & 005 & \multicolumn{5}{|l}{} \\
\hline
\end{tabular}

\section{At 193.4 THz}

\begin{tabular}{|l|l|l|l|l|}
\hline $\begin{array}{l}\text { Sr. } \\
\text { No } \\
.\end{array}$ & Parameter & $\begin{array}{l}\text { Pre- } \\
\text { compensati } \\
\text { on }\end{array}$ & $\begin{array}{l}\text { Post- } \\
\text { compensat } \\
\text { ion }\end{array}$ & $\begin{array}{l}\text { mix- } \\
\text { compensat } \\
\text { ion }\end{array}$ \\
\hline 1 & Q- FACTOR & 16.2188 & 33.0433 & 16.9353 \\
\hline 2 & BER & $\begin{array}{l}1.15785 \mathrm{e}-0 \\
59\end{array}$ & $\begin{array}{l}6.30161 \mathrm{e}- \\
240\end{array}$ & $\begin{array}{l}7.92785 \mathrm{e}- \\
065\end{array}$ \\
\hline 3 & EYE & 0.0008100 & 0.0005482 & $\begin{array}{l}7.89927 \mathrm{e}- \\
005\end{array}$ \\
\hline 4 & HEIGHT & 5 & 44 & $\begin{array}{l}7.78197 \mathrm{e}- \\
006\end{array}$ \\
\hline
\end{tabular}

\section{At 193.6 THz}

\begin{tabular}{|c|c|c|c|c|}
\hline $\begin{array}{l}\text { Sr. } \\
\text { No }\end{array}$ & Parameter & $\begin{array}{l}\text { Pre- } \\
\text { compensat } \\
\text { ion }\end{array}$ & $\begin{array}{l}\text { Post- } \\
\text { compensat } \\
\text { ion }\end{array}$ & $\begin{array}{l}\text { Mix- } \\
\text { compensat } \\
\text { ion }\end{array}$ \\
\hline 1 & Q- FACTOR & 12.8168 & 18.3711 & 8.43951 \\
\hline 2 & BER & $\begin{array}{l}5.95953 \mathrm{e}- \\
038\end{array}$ & $\begin{array}{l}\text { 9.52577e- } \\
076\end{array}$ & $\begin{array}{l}1.53839 \mathrm{e}- \\
017\end{array}$ \\
\hline 3 & $\begin{array}{l}\text { EYE } \\
\text { HEIGHT }\end{array}$ & $\begin{array}{l}0.0001074 \\
6\end{array}$ & $\begin{array}{l}8.15271 \mathrm{e}- \\
005\end{array}$ & $\begin{array}{l}1.01206 \mathrm{e}- \\
005\end{array}$ \\
\hline 4 & $\begin{array}{l}\text { THRESHOL } \\
\text { D }\end{array}$ & $\begin{array}{l}4.30204 \mathrm{e}- \\
005\end{array}$ & $\begin{array}{l}2.59962 \mathrm{e}- \\
005\end{array}$ & $\begin{array}{l}7.34677 \mathrm{e}- \\
006\end{array}$ \\
\hline
\end{tabular}

\section{At $193.8 \mathrm{THz}$}

\begin{tabular}{|c|c|c|c|c|}
\hline $\begin{array}{l}\text { Sr. } \\
\text { No }\end{array}$ & Parameter & $\begin{array}{l}\text { Pre- } \\
\text { compensati } \\
\text { on }\end{array}$ & $\begin{array}{l}\text { Post- } \\
\text { compensat } \\
\text { ion }\end{array}$ & $\begin{array}{l}\text { Mix- } \\
\text { compensat } \\
\text { ion }\end{array}$ \\
\hline 1 & Q- FACTOR & 7.39102 & 9.93917 & 4.34596 \\
\hline 2 & BER & $\begin{array}{l}7.10346 \mathrm{e}-0 \\
14\end{array}$ & $\begin{array}{l}1.36632 \mathrm{e}- \\
023\end{array}$ & $\begin{array}{l}6.93234 \mathrm{e}- \\
006\end{array}$ \\
\hline 3 & $\begin{array}{l}\text { EYE } \\
\text { HEIGHT }\end{array}$ & $\begin{array}{l}2.3297 \mathrm{e}-00 \\
5\end{array}$ & $\begin{array}{l}1.86313 \mathrm{e}- \\
005\end{array}$ & $\begin{array}{l}1.16029 \mathrm{e}- \\
006\end{array}$ \\
\hline 4 & $\begin{array}{l}\text { THRESHOL } \\
\text { D }\end{array}$ & $\begin{array}{l}1.88935 \mathrm{e}-0 \\
05\end{array}$ & $\begin{array}{l}1.37525 \mathrm{e}- \\
005\end{array}$ & $\begin{array}{l}3.03232 \mathrm{e}- \\
006\end{array}$ \\
\hline
\end{tabular}

\section{CONCLUSION}

The three dispersion compensation techniques using DCF (pre-, post- and mix-compensation) are compared in terms of BER, Q-factor, eye height and threshold. We observed that the post-compensation technique performs better than the preand mix-compensation using DCF for dispersion compensation in 40Gb/s WDM system is an effective solution. The attenuation of DCF fiber is not null. Thus, the attenuation of DCF fiber will produce impairment to the signal quality as well as that of SMF. As earlier discuss the influence of attenuation can be compensated with optical fiber amplifier such as EDFA. Post-compensation technique can greatly reduce the fiber nonlinear effects and this performs better than the pre compensation and mix compensation program schemes.

\section{REFERENCES}

[1] Bo-ning HU, Wang Jing, Wang Wei, Rui-mei Zhao, "Analysis on Dispersion Compensation with DCF based on Optisystem". 2nd International Conference on Industrial and Information Systems pp. 40-43 2010.

[2] Mochida Y, Yamaguchi N, Ishikawa G, "Technologyoriented review and vision of $40 \mathrm{~Gb} / \mathrm{s}$-based optical transport Networks", Journal of light-wave technology .PP. 2272-22, 12002,20(12)

[3] Zhang Hongb in, Q IU Kun, "Emulation of characteristics of optical fiber transmission for a $10 \mathrm{~Gb} / \mathrm{s}$ single channel situation," act a photonica sinica 2001 vol.30 No.6 715720

[4] Omae T, "Universal conditions for estimating the nonlinear refractive index $\mathrm{n} 2$ of dispersion compensating fibers by the CW- 43 SPM method", IEEE Photon. Technol. Lett., Vol 13. No.6, pp. 571-573, Nov, 2001.

[5] Mohammad. Amin. Dallaali, "Malin Premaratne power and dispersion constrained optimization of optical links with unequally spaced repeater modules", Optical Fiber Technology, Vol 13, No 4, pp.309-317, October. 2007.

[6] Zou X Y, Hayee M I, H Wang S M, et al. Limitations in $10 \mathrm{~Gb} / \mathrm{s}$ WDM optical-fiber transmission when using a variety of fiber types to manage dispersion and nonlinearities [J]. Light wave Technol., PP: 1144-1152, June, 1996

[7] WuQiang, Yu Chong Xiu, "Analysis on dispersion compensation with DCF", semiconductor optoelectronics, Vol.24 No.3 pp.186- 196.June 2007

[8] Zhaohuaigang, "study on dispersion compensation in optical transmission system", study pn optical communications, Vol.3, No.141, 2007

[9] Wangchen, Raomin, "the performance of the DCF Transmission system", Journal of applied sciences, Vol.21, No.2, pp.177-181, June 2003.

[10] Djafar K. Mynbaev Lowell L. Scheiner, Fiber-optic communications technology. Beijing: Science publishing company, 2002

[11] Jianjun Yu, Bojun Yang,"Dispersion-allacated soliton technology with long amplifier spacing and long distance," IEEEphoton technol lett, vol 9, pp. 952-954, No.7, 1997:

[12] Killy R I, Thiele H J, Mikhailov v, ea al. Reduction of intrachannel nonlinear distortion in 40-Gb/s based WDM transmission over standard fiber [J]. IEEE Photonics Technology Letters, 2000, 12(12): 1642-1626

[13] ZhouZhiQiang, TangYuLiang, "Optimmum schemes of dispersion compensation transmission systems using dispersion compensation fibers", laser technology, VoI.24,No.5, pp.265-269 Oct.2000. 